\title{
Analysis and comparison of Smart City initiatives
}

\author{
Aranzazu FERNÁNDEZ-VÁZQUEZ ${ }^{1}$ and Ignacio LÓPEZ-FORNIÉS ${ }^{1}$ \\ ${ }^{1}$ Department of Design and Manufacturing Engineering, María Luna 3, Zaragoza, 50018, Spain. \\ * Tel.: +34-669-390-186; fax: +34 9767622 35; E-mail address: aranfer@unizar.es
}

\begin{abstract}
Complexity in cities is expected to become even higher in the short term, which implies the need to face new challenges. The Smart City (SC) model and its associate initiatives have become very popular for undertaking them but it is not often very clear what it really means. Starting with a previous classification of the initiatives developed under the SC model into two big categories, according to their approach to citizens, this paper aims to make a critical analysis of this model of city, and to propose the development of new initiatives for it based on Citizen-Centered Design methodologies. Living Labs, both as methodology and as organization, appear in this context as an interesting choice for developing initiatives with real citizen involvement along the entire design process, which it is expected to arise in later stages of research.
\end{abstract}

Keywords: Smart City, Living Lab, Citizen Centered Design, Design methods.

\section{Introduction}

Over the last decades cities have been facing new challenges that are expected to become even bigger in the short term. The fact that $54 \%$ of world's population live in cities [1], and the expectation that it will increase up to $66 \%$ by 2050 , are incessantly repeated data that appears in almost every paper or publication regarding urban planning or cities [2][3][4]. These facts are usually used for highlighting the urgency with which new approaches must be made to improve citizens' conditions now and for the near future.

In this context, many models have emerged claiming to be the solution for the upcoming challenges: eco-city, high-tech city or real-time city. One of the most successful ones is Smart City (SC), and many initiatives and much research have been developed in recent years around it. The objective of this study is to make a critical analysis of different initiatives developed within this model based on the role of citizens in each one of them. Citizen implication is a fact that can guarantee 
the success of the initiatives and its economic and social viability, which is of major interest for all the parties involved in the develop of cities [5][6]. According to the results of the investigation, it is intended, in the following phase of this research, to develop new initiatives for the SC based on citizens' interest, integrating user-centered design methodologies.

It becomes clear that intensive research and numerous proposals have been developed under the SC label lately, but yet there is not a unique definition for SC, and the indicators of the "smartness" of a city are still far from indisputable [7]. Nevertheless, the analysis of urban governance has appeared as a promising approach for measuring the impact of innovation in urban daily processes [8], and for this end, it is interesting to analyse the role of citizen in the whole process.

Thus, analysing publications of the last fifteen years, more than one thousand research articles can be found in Scopus with "smart cities" within their title. In those, two broad categories can be established on SC initiatives when it regards to the role of the citizens:

- The first, more abundant in publications, comprises proposals that focus on the integration of Information and Communication Technologies (ICT) to city services and infrastructure. In general, they respond to a top-down approach, in which the initiatives are mainly developed by administrations and/or companies, with citizens as mere end users.

- The second one, in some ways opposite, includes initiatives that pose a redefinition of the ICT approach, and offers a user-centered design focus. It responds to a bottom-up approach, in which citizen participation is encouraged throughout the process.

\section{Smart City models and initiatives based on ICT}

\subsection{Technological definitions of SC}

The first approach defines SC as the city that is using new ICT's innovatively and strategically to achieve its aims. According to this definition, the Smart City is characterized by its ICT infrastructures, which facilitate an urban system increasingly, smart, interconnected and sustainable [2].

The paradigm that supports the need of this ICT deployment is the Internet of Things (IoT), which proposes a system in which the pervasive presence of a variety of devices able to interact with each other without the intervention of people. In this context, SC is driven and enabled by interconnected objects placed in the urban space. Based in technology such as modern wireless sensing machine to machine (M2M), Radio Frequency Identification (RFID) or Wireless Sensor Networks (WSN), IoT is supposed to successfully contribute to a more efficient and 
accurate use of the resources [9], allowing access to a large amount of information (Big Data) that can be processed for its subsequent use by data mining techniques.

The futuristic concept of a SC where citizens, objects, utilities, etc., are seamlessly connected using ubiquitous technologies is almost a reality, so as to significantly enhance the living experience in 21 st century urban environments [10]. Proposals undertaken with this approach have been developed within the field of transport, services and energy efficiency of cities, and all those related with big data and data mining, can be included within this approach too. Many of them also have been supported, promoted and/or advertised by large ICT's companies, such as Endesa-Enel and IBM in Malaga (Spain), IBM in Songdo City (South Korea), TECOM Investments in SmartcityMalta (Malta), Cisco Systems in Holyoke, Massachusetts (USA) and Telefonica in Santander (Spain).

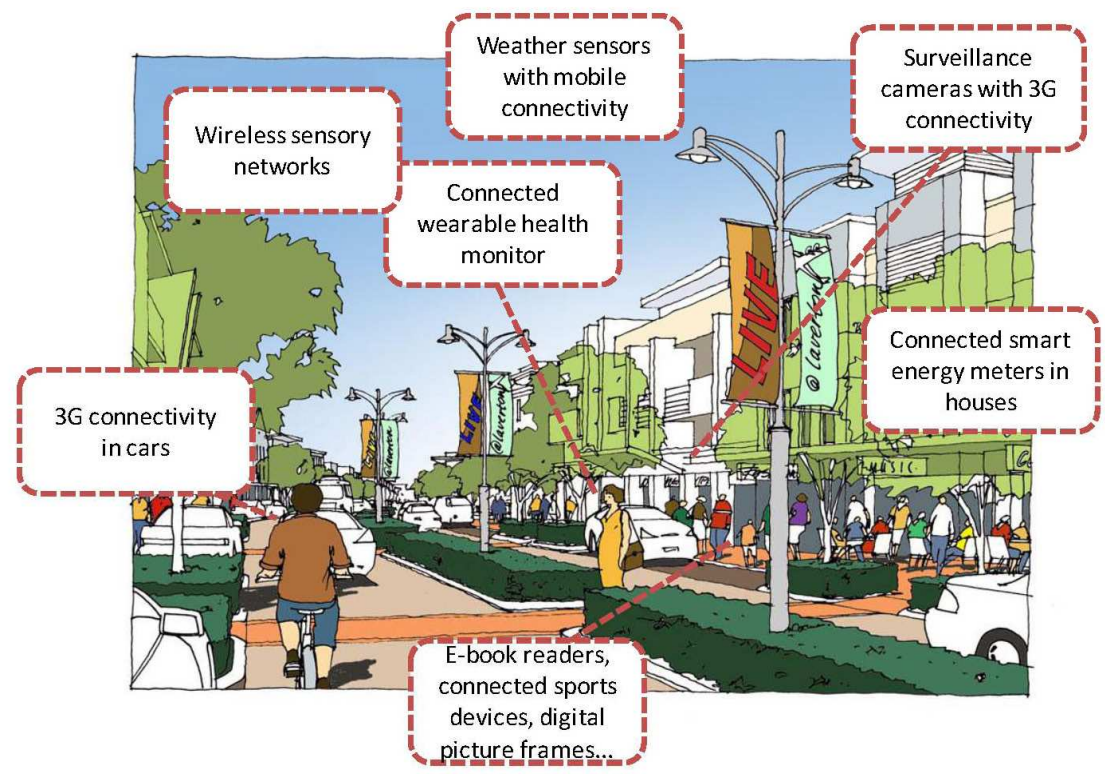

Fig. 1. Typical IoT approach Smart City representation [6]

But this point of view has not only been encouraged by companies. The European Commission itself started promoting a SC model with bigger focus on energy efficiency, renewable energy and green mobility than in citizens themselves [11]. This tendency has slightly changed recently, but not significantly yet.

This issue has also been the subject of much academic research, mainly within the fields of Computer and ICT sciences. Therefore, the investigation has focus primarily on issues such as the architecture protocols and infrastructure needed for the deployment of this model, as mobile crowd sensing (MCS) [12], or adaptations of previously existent architectures, such as Extensible Messaging and Presence Protocol (XMPP) [13], for developing new services for this city model. 


\subsection{ICT based SC initiatives: problems and redefinition}

The previous definition of SC and its associated initiatives has, however, been questioned [14][15][16][17]. On the one hand, it has been argued that while there were no general consensus on the meaning of the SC term or what its describing attributes were, there have been an intensive "wiring" of cities and the collection of big amounts of information, without consideration of some of the possible associated problems, such as the need of ensure the privacy of participants when data are collected by directly instrumenting human behaviour [14]. Accordingly, "cities often claim to be smart, but do not define what this means, or offer any evidence to support such proclamations" [15].

On the other hand, when analysing most of the initiatives developed within the field of SC, it can be seen that the results only slightly resemble their ambitious initial objectives. It appears to become difficult to "transform the higher level concepts found in SC literature into actionable and effective policies, projects and programs that deliver measurable value to citizens" [16]. With pressure growing for cities to get even smarter, smart city claims have a self-congratulatory nature that is causing a kind of anxiety around the development of this model [17].

\section{Smart City initiatives based on Citizens}

In response to the problems arising from the technological predominant SC model, a current of opinion has claimed that the design of the genuine smart city only could be possible by the emergence of smart citizens, who would be the ones that will conferred the "smart" attribute to cities [18] [19].

Instead of considering people as just another one of the enabling forces of the SC [20], these proposals have opted for the application of citizen-centric and participatory approaches to the co-design and development of Smart City. This model is emerging as a new and specific type of SC, the Human Smart City [21].

In spite of that, most of the proposals in which the emergence of smart citizens is supposedly intended have limited citizen's participation to roles of data provider [22] or tester of a pre-designed model or service [23], but on rare occasion have implicated them in the entire process. The main exception, and the environment that has made possible the emergence of projects in which citizens have played a major role throughout the entire process, have been the experiences of Living Labs developed in the field of SC. 


\subsection{Living Labs general definition and first SC experiences}

Living Labs (LL) have been defined both as a research and development methodology and as the organization that is created for its practice [24], and many times it also refers to the context or space in which is developed.

As a methodology, LL is one in which innovations are created and validated in collaborative, multi-contextual and multi-cultural empirical real-world environments [25]. This approach seeks for the implication of users in every phase of the process as the mean to ensure their engagement with the services or products developed, and it is performed through iterative cycles of proposal, development of alternatives and testing at every stage of the process. Thereby, it can be considered a User Centered Design (UCD) methodology for the way in which user involvement is encouraged.

Referring to LL as an organization, many European cities have established their own ones for developing new initiatives. The European organization that brings together most of this LL is the European Network of Living Labs (ENoLL) [26], which was legally established as an international association in 2.010, and it has developed since then all kind of initiatives for spreading its aims, methods and objectives.

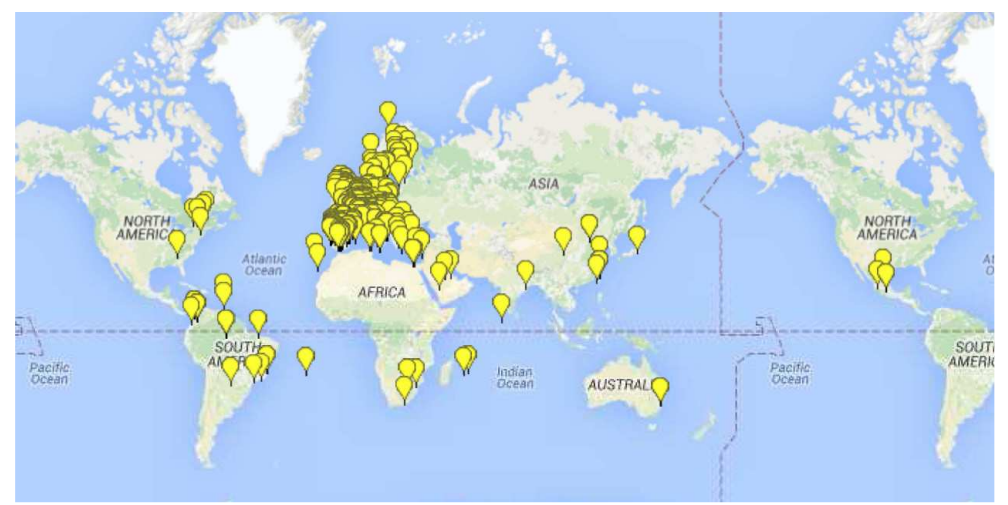

Fig. 2. Map of existing LL according to ENoLL Web Site [20]

From the beginning, LL have focused in developing new business models, mainly in technical and industrial contexts. And due to the lack of definition of the SC and the difficulty of city leaders to identify the quantifiable sources of value that ICT networks can generate for them, this focus have made LL appear as an ideal candidate to create an appropriate model for the implementation of the SC [27] [28]..

These SC LL have aimed at improving the governance of cities, promoting proposals coming from citizens themselves and applying user-centered design methodologies, such as co-design or service design [29][30] [31]. 


\subsection{Living Labs problems regarding $S C$}

Considering the experiences and studies developed, it is not so clear which category of methodologies LL could be included in. Although it has been claimed to be a User Driven methodology, one of the main problems of European LL has been the difficulty for citizens to forward their initiatives and ideas to the LL, so users can not be considered as those who actually run the innovation process. According to that, LL could be better considered as a methodology between User Centered Design and Participatory Design. But much investigation is yet needed for defining the characteristics and potentials of LL methodologies [32].

Besides, it has been difficult to create a really consistent audience for these initiatives, so that sometimes the results are not significant or do not allow to obtain sufficient data for processing. It has got difficult, mainly in countries with little tradition of citizen involvement such as Spain, to get citizens involved implicated in those projects. As the common good, understood as the social benefit achieved by citizenship by the active participation in the realm of politics and public services, has not been interiorized as desirable by society, the social benefit finally is not achieved. Thus, many of the projects have remained in academia.

Finally, initiatives related to LL have still relied largely on the involvement of an administration for its development, which on one hand has limited its scope of action because of the context of crisis of recent years. And on the other hand, it has been paid little attention to cost-effectiveness in LL projects, which can hinder a future sustainable financing for private stakeholders.

\section{Summary and Benchmarking of SC initiatives}

It can be occasionally confusing to distinguish between initiatives, and ICT based ones often seem to adopt a citizen driven approach, as by establishing a distinction between so-called "hard" and "soft" domains, and including under the "soft" definition all those related to governance and people [33]. But a clear distinction can be made between the two models by analysing the indicators shown in Table 1. Some of these indicators have been previously explained in the previous sections, such as the leaders and drivers of the process in each category, or their characteristic features.

The facts have been extracted from experiences exposed by international organizations, such as the previously mentioned ENoLL, or in cities web pages. This information has been completed with searches in SCOPUS within the smart city term in combination with "ICT", "citizen", "user" and, finally, "Living Labs". These searches have been made since 2013, and after filter the information, for eliminate irrelevant information, more than 200 articles were analysed for obtaining the facts exposed. 
Table 1. Benchmarking of SC models.

\begin{tabular}{|c|c|c|}
\hline & ICT based SC & Citizen based SC \\
\hline $\begin{array}{l}\text { Leaders and } \\
\text { drivers }\end{array}$ & $\begin{array}{l}\text { ICT/Energy/Utility companies } \\
\text { City policy actors }\end{array}$ & $\begin{array}{l}\text { Neighbourhood associations } \\
\text { Small collectives }\end{array}$ \\
\hline Beneficiary & $\begin{array}{l}\text { Companies, Authorities and } \\
\text { Citizens (partially) }\end{array}$ & Citizens and Involved collectives \\
\hline Innovation base & Technological based & Open or collaborative innovation \\
\hline $\begin{array}{l}\text { Objectives \& } \\
\text { priorities }\end{array}$ & $\begin{array}{l}\text { Urban development } \\
\text { Infrastructure improvements } \\
\text { Efficient spending }\end{array}$ & $\begin{array}{l}\text { Social welfare } \\
\text { Common good } \\
\text { Engagement of citizens }\end{array}$ \\
\hline Resources & $\begin{array}{l}\text { Public resources } \\
\text { Private investment }\end{array}$ & $\begin{array}{l}\text { Individual funds } \\
\text { Crowdfunding }\end{array}$ \\
\hline $\begin{array}{l}\text { Characteristic } \\
\text { Features }\end{array}$ & $\begin{array}{l}\text { Networks } \\
\text { ICT Devices } \\
\text { Data Collection }\end{array}$ & $\begin{array}{l}\text { Citizen participation } \\
\text { Open clouds and platforms } \\
\text { Social services }\end{array}$ \\
\hline Pros & $\begin{array}{l}\text { Secured funding for projects } \\
\text { Big media power } \\
\text { Data mining resources }\end{array}$ & $\begin{array}{l}\text { Secured citizen engagement } \\
\text { Targeted initiatives } \\
\text { Focus towards Common good }\end{array}$ \\
\hline Cons & $\begin{array}{l}\text { Poor citizen participation } \\
\text { Fuzzy goals } \\
\text { Private benefits } \\
\end{array}$ & $\begin{array}{l}\text { Lack of funds } \\
\text { Poor communication power } \\
\text { Need for new tools/methods }\end{array}$ \\
\hline
\end{tabular}

Although Citizen based SC initiatives rely on co-creative and collective processes with involved groups of people that can be autonomous, ICT features can become a very strong support. It is only necessary to re-think the idea of city we are heading to.

\section{Conclusions and further research}

The notion of Smart City on the one hand refers to cities that are increasingly composed of and monitored by pervasive and ubiquitous computing, and, on the other hand, to those whose economy and governance is being driven by innovation, creativity and entrepreneurship, enacted by smart people. 
However, it does not seem to be a clear way of linking the two ideas into specific initiatives, and only the experiences arose in the so called "living labs" could be considered close to have reached a proper convergence between the two models, by involving citizens throughout the whole process while integrating ICT in a proper way. But they are not large in number or homogeneous in characteristics and scope, and have had limited citizens participation and involvement. Further, the dissemination of the results has not been enough to promote similar initiatives, and the dependence on administration involvement can hinder their future.

LL characteristics are anyway very promising from the designer's perspectives, as they allow the emergence of new processes that can develop real and better user involvement in SC. The integration of citizen-driven processes for fostering participation in the early stages of the initiatives or the search for new communication channels for allowing better result dissemination are just two of the possible research fields for the near future.

It is our intention to try to develop in the short term a pilot project in the field of SC using LL Design Methods and Citizen-Driven processes. The participation of citizens along the entire design process might ensure that the product or service will meet a real need in a proper way, which it is very interesting for companies and administrations, thereby achieving the involvement of all stakeholders and ensuring the viability of the initiatives. And as it would imply that throughout the process user participation would be sought, the promotion of citizen creativity and entrepreneurship would be also achieved.

\section{References}

1. United Nations. World Urbanization Prospects: The 2014 Revision. 2.014. New York.

2. Kumar Debnath A., Chor Chin H., Haque M. and Yuen B. A methodological Framework for benchmarking smart transport cities. Cities, 2014, 37, pp.47-56.

3. Jair Cabrera, O. Infraestructuras que dan soporte a ciudades inteligentes. CONACYT symposium for scholars and former grantees. 2012. Available at: http://docplayer.es/7437135Ponencia-oscar-jair-cabrera-bejar.html [last date of access: 18/04/2016]

4. Karada $\breve{g}, T$. An evaluation of the smart city approach. Doctoral Dissertation, 2013._Middle East Technical University.

5. Macintosh, A. Using Information and Communication Technologies to Enhance Citizen Engagement in the Policy Process, in OECD, Promise and Problems of E-Democracy: Challenges of Online Citizen Engagement, OECD Publishing, Paris. 2004. DOI: http://dx.doi.org/10.1787/9789264019492-3-en

6. De Lange, M, De Waal, Mn. Owning the city: New media and citizen engagement in urban design, First Monday, [S.1.], nov. 2013. ISSN 13960466, available at: http://pear.accc.uic.edu/ojs/index.php/fm/article/view/4954/3786. Date accessed: 14/06/2016.

7. Manville, $\mathrm{C}$ et al. Mapping smart cities in the EU. 2014. Available at: http://www.rand.org/pubs/external publications/EP50486.html. Date accessed: 14/06/2016

8. Anthopoulos, L. G., Janssen, M., \& Weerakkody, V. Comparing Smart Cities with different modeling approaches. In Proceedings of the 24th International Conference on World Wide 
Web Companion, May 2015, pp. 525-528, International World Wide Web Conferences Steering Committee.

9. Jin, J. Gubbi, J. Marusic, S. \& Palaniswami, M. An information framework for creating a smart city through internet of things. Internet of Things Journal, IEEE, 2014, 1(2), 112-121.

10. Dohler M. Vilajosana I., Vilajosana X. \& LLosa, J. Smart cities: An action plan. In Barcelona Smart Cities Congress. Barcelona, Spain, December 2011,

11. Centre of Regional Science, Vienna UT. Smart cities - Ranking of European medium-sized cities. Final Report. 2012. Available at: http://www.smart-cities.eu/press-ressources.html. Date accessed: 18/04/2016.

12. Cardone C., Cirri A., Corradi A., Foschini L. The ParcipAct Mobile Crowd Sensing Living Lab: The Testbed for Smart Cities. IEEE Communications Magazine, 2014, 52(10), 78-85.

13. Szabo R. et al. Framework for Smart City Applications based on Participatory sensing. In $4^{\text {th }}$ IEEE International Conference on Cognitive Infocommunications. Budapest, Hungary, 2013

14. Stopczynski A., Pietri R., Pentland A., Lazer D., Lehmann, S. Privacy in sensor-driven human data collection: A guide for practitioners. 2014. arXiv preprint arXiv:1403.5299.

15. Holland R. Will the real Smart City please stand up? Creative, progressive or just Entrepreneurial. City, 2008, 12 (3), 302-320.

16. Cosgrave E., Arbuthnot K., Tryfonas, T. Living labs, innovation districts and information marketplaces: A systems approach for smart cities. Procedia Computer Science, 16, 2013, pp. 668-677.

17. Allwinkle S., Cruickshank, P. Creating smart-er cities: An overview. Journal of urban technology, 2011, 18 (2), 1-16.

18. Department for Business Innovation \& Skills, Smart Cities. Background paper, available at: https://www.gov.uk/government/publications/smart-cities-background-paper, 2013. Date accessed: 14/06/2016.

19. Haque, U. (2012). Surely there's a smarter approach to smart cities?. Wired, 17, 2012-04.

20. TECNO - Cercle Tecnològic de Catalunya. Hoja de Ruta para la Smart City. Available from: http://www.socinfo.es/contenido/semina-rios/1404smartcities6/03-ctecno_hoja_ruta_smartcity.pdf. Date accessed: 18/04/2016.

21. Marsh J., Molinari F., Rizzo F. Human Smart Cities: A New Vision for Redesigning Urban Community and Citizen's Life. In Knowledge, Information and Creativity Support Systems: Recent Trends, Advances and Solutions. 2016. pp. 269-278. (Springer International Publishing).

22. https://smartcitizen.me/ [last date of access: 15/04/2016].

23. https://stormclouds.eu/ [last date of access: 15/04/2016].

24. Almirall, E., Lee, M., \& Wareham, J. Mapping living labs in the landscape of innovation methodologies. Technology Innovation Management Review, 2012, 2(9), 12.

25. Schumacher J., Feurstein, K. Living Labs - the user as co-creator. 2007.

26. http://www.openlivinglabs.eu/

27. Cosgrave E., Arbuthnot K., Tryfonas, T. Living labs, innovation districts and information marketplaces: A systems approach for smart cities. Procedia Computer Science, 16. 2013, pp. 668-677.

28. Eskelinen, J., Garcia Robles, A., Lindy, I., Marsh, J., \& Muente-Kunigami, A. CitizenDriven Innovation (No. 21984). The World Bank. 2015.

29. http://humansmartcities.eu/project/apollon/

30. http://my-neighbourhood.eu/

31. http://www.opencities.net/node/66

32. Dell'Era, C., Landoni, P. Living Lab: A Methodology between User - Centered Design and Participatory Design. Creativity and Innovation Management, 2014, 23(2), 137-154.

33. Neirotti, P., De Marco, A., Cagliano, A. C., Mangano, G., \& Scorrano, F. Current trends in Smart City initiatives: Some stylised facts. Cities, 2014, 38, pp.25-36. 